\title{
Abiraterone versus bicalutamide in combination with gonadotropin releasing hormone antagonist therapy for high risk metastatic hormone sensitive prostate cancer.
}

Takashi Ueda ( $\boldsymbol{\nabla}$ t-ueda@koto.kpu-m.ac.jp )

Kyoto Prefectural University of Medicine

Takumi Shiraishi

Kyoto Prefectural University of Medicine

Saya Ueda

Kyoto Prefectural University of Medicine Motoharu Ohashi

Kyoto Prefectural University of Medicine

Toru Matsugasumi

Kyoto Prefectural University of Medicine

Yasuhiro Yamada

Kyoto Prefectural University of Medicine

Atsuko Fujihara

Kyoto Prefectural University of Medicine

Fumiya Hongo

Kyoto Prefectural University of Medicine

Koji Okihara

Kyoto Prefectural University of Medicine

Osamu Ukimura

Kyoto Prefectural University of Medicine

\section{Research Article}

Keywords: abiraterone, bicalutamide, gonadotropin-releasing hormone antagonist, high risk metastatic hormone sensitive prostate cancer

Posted Date: March 5th, 2021

DOI: https://doi.org/10.21203/rs.3.rs-269640/v1 
License: (c) (i) This work is licensed under a Creative Commons Attribution 4.0 International License. Read Full License 


\section{Abstract}

\section{Objectives}

To compare the efficacy of abiraterone with that of bicalutamide in combination with gonadotropinreleasing hormone antagonist treatment for high risk metastatic hormone-sensitive prostate cancer patients.

\section{Methods}

One hundred and forty-nine patients with high risk metastatic hormone-sensitive prostate cancer at our hospital and affiliated hospitals between December 2013 and July 2020 were retrospectively identified. Fifty patients were administered abiraterone $(1000 \mathrm{mg} /$ day) plus prednisolone $(5 \mathrm{mg} /$ day) with gonadotropin-releasing hormone antagonist (degarelix) (group A) and 99 patients were administered bicalutamide (80mg/day) with gonadotropin-releasing hormone antagonist (group B).

\section{Results}

PSA- progression-free survival of group A was significantly longer than that of group B. Abiraterone therapy and Gleason score were significant independent factors for PSA-progression-free survival. By propensity score matching, total 56 matched patients were obtained. PSA-PFS $(p<0.001)$ and OS $(p=0.0071)$ of high risk mHNPC patients were significantly longer in abiraterone group of matched patients. Abiraterone therapy and Gleason score were still shown to be significant independent factors for PSA-PFS in matched patients.

\section{Conclusions}

PSA-progression-free survival and overall survival in patients who were treated with abiraterone in combination with gonadotropin releasing hormone antagonist were significantly better than those of bicalutamide.

\section{Introduction}

Though prostate cancer today tends to be diagnosed at early stage due to the introduction of PSA screening, some patients with prostate cancer still present metastasis at the time of diagnosis in Japan 12. Androgen deprivation therapy (ADT) as systemic therapy is generally accepted as a standard of care for patients with metastatic hormone-sensitive prostate cancer (mHSPC). In Japanese clinical practice guideline for prostate cancer, combined androgen blockade (CAB) therapy, which involves concurrent use of a gonadotropin-releasing hormone $(\mathrm{GnRH})$ agonist and first-generation antiandrogen such as bicalutamide is recommended as the standard first-line therapy for metastatic prostate cancer. On the other hand, CAB therapy is not recommended in National Comprehensive Cancer Network guidelines and European Association of Urology guidelines ${ }^{3}$. 
Recently, hormonal therapy using abiraterone, next-generation antiandrogen, was reported to improve overall survival (OS) and radiographic progression-free survival (PFS) in men with high risk mHSPC who exhibit at least two of the three following factors: 8 or more Gleason score, 3 or more bone lesions, and the presence of visceral metastasis ${ }^{4}$. Though the superiority of abiraterone plus prednisone with $\mathrm{GnRH}$ agonist to placebo with $\mathrm{GnRH}$ agonist for treatment of high risk mHSPC had been shown in the report, there are two concerns to apply this result into clinical practice in Japan. First, as stated above, most of metastatic prostate cancer patients receive CAB therapy as first-line therapy in Japan ${ }^{5}$. Therefore, the effectiveness of abiraterone plus prednisone with $\mathrm{GnRH}$ analog should be compared with that of $C A B$ therapy using bicalutamide. Second, GnRH antagonist, degarelix, which doesn't induce a transient rise in testosterone to aggravate the symptoms, instead of $\mathrm{GnRH}$ agonist are becoming major component of ADT especially for those who have a high metastatic burden in Japan ${ }^{6}$. However, there has been no reports to compare the efficacy of abiraterone with that of bicalutamide in combination with $\mathrm{GnRH}$ antagonist treatment for high risk $\mathrm{mHSPC}$.

The aim of this study was to compare the efficacy of abiraterone with that of bicalutamide in combination with $\mathrm{GnRH}$ antagonist treatment for high risk $\mathrm{mHSPC}$.

\section{Methods}

\section{Patients and Treatments}

We retrospectively identified 149 patients with high risk $\mathrm{mHSPC}$ at our hospital and affiliated hospitals in KPUM-Prostate Cancer Study Group between December 2013 and July 2020. All patients have two or more following factors: 8 or more Gleason score, at least three bone lesions, and the presence of visceral metastasis. Fifty patients were administered abiraterone $(1000 \mathrm{mg} /$ day) plus prednisolone $(5 \mathrm{mg} /$ day $)$ with GnRH antagonist (degarelix) (group A). Ninety-nine patients who were administered bicalutamide (80mg/day) with $\mathrm{GnRH}$ antagonist were categorized as group B.

Bone and visceral metastasis were assessed by bone scintigraphy and computed tomography (CT).

Extent of disease (EOD) score was measured by bone scintigraphy. This study was approved by the institutional review board of Kyoto Prefectural University of Medicine (ERB-C-1071-2) and each affiliated hospitals and conducted in compliance with the Declaration of Helsinki. The institutional review board waived individual written informed consent due to the retrospective nature of this study.

\section{Statistical Analysis}

The chi-square test and Wilcoxon's rank sum test was used to compare the two groups as appropriate. Kaplan-Meier analysis was used for estimation of the differences in time events between the two groups using the log-rank test. Cox's proportional hazard models were applied to investigate factors associated with progression free survival. Propensity score matching technique was used to adjust the clinical backgrounds between two groups. Statistical analyses were performed using SAS JMP, Version 14, and $\mathrm{P}<0.05$ was taken to indicate statistical significance. 


\section{Results}

\section{Clinical background of the patients}

Table 1 shows clinical background of the patients. Fifty patients were administered abiraterone plus prednisolone with $\mathrm{GnRH}$ antagonist (degarelix) (group A). Ninety-nine patients were administered bicalutamide with $\mathrm{GnRH}$ antagonist (group $B$ ). There were no significant differences between group $A$ and group $B$ in terms of pretreatment PSA ( $p=0.554)$. The patients of group A was significantly younger than those of group B $(p<0.001)$. Pretreatment ALP level, Gleason score and EOD score of group A were significantly higher than those of group $B(p=0.0411,0.0439$ and 0.0402$)$, indicating that patients of group A have more advanced and aggressive disease compared to those of group $B$. The significant shorter observation period of group $A(p<0.001)$ was probably due to the late approval of abiraterone in Japan.

\section{Prognostic factor of PSA progression free survival}

As shown in Figure S1, PSA-PFS of group A was significantly longer than that of group B. It has been reported that age, pretreatment PSA level, Gleason score, EOD score and pretreatment ALP level were prognostic factors associated with PSA control in mHNPC treatment ${ }^{78}$. Therefore, we performed Cox Logistic regression analysis to investigate factors associated with PSA-PFS in patients with high risk mHSPC using variables of those factors in addition to antiandrogen use (abiraterone or bicalutamide). Abiraterone therapy and Gleason score were shown to be significant independent factors for PSA-PFS in high risk mHNPC treatment (Table. 2). However, OS of high risk mHNPC was not significantly different between two groups (Figure S2).

\section{The difference of effectiveness between abiraterone and bicalutamide for high risk mHNPC patients adjusted by propensity score matching technique.}

Because several factors associated with PSA-PFS and OS were significantly different between two groups (group A and B) (Table1), we next used propensity score matching technique to adjust these clinical backgrounds between two groups to examine the difference for high risk mHNPC patients more precisely. Total 56 matched patients were obtained from 149 patients. As described in Table 3, clinical backgrounds were well adjusted between the two groups. PSA-PFS $(p<0.001)$ and OS $(p=0.0071)$ of high risk mHNPC patients were significantly longer in abiraterone group of matched patients (Fig.1 and 2). Abiraterone therapy and Gleason score were still shown to be significant independent factors for PSAPFS in matched patients (Table 4).

\section{Discussion}

In this study we retrospectively compared the efficacy of abiraterone with that of bicalutamide in combination with GnRH antagonist treatment for high risk MHNPC and found that PSA-PFS and OS in patients who were treated with abiraterone were significantly better than those of bicalutamide. 
In western countries, $C A B$ therapy is rarely used as the standard first-line therapy for metastatic prostate cancer, while in Japan it has been widely accepted since several previous reports had suggested that Japanese prostate cancer patients respond to CAB therapy more effectively than other races ${ }^{9}$. For example, it is reported that the adjusted prostate cancer-specific mortality in Japanese prostate cancer patients who received CAB therapy is less than half of those in USA patients ${ }^{10}$. Several reasons such as genetic and dietary/environmental factors have been discussed to explain the discrepancy between countries ${ }^{11}$. Furthermore, the difference in typical dosage of bicalutamide $(80 \mathrm{mg} /$ day in Japan vs $50 \mathrm{mg}$ in western countries) has also been accounted for the controversial results ${ }^{12}$. In fact, another report has also suggested that the dose of bicalutamide is associated with PSA response ${ }^{13}$. In another study, Mathew RC et al. reported that CAB therapy improved survival more significantly compared to $\mathrm{LH}-\mathrm{RH}$ monotherapy in men with very-high-risk metastatic disease, but not with lower risk metastatic tumors, indicating that $\mathrm{CAB}$ therapy may be more effective especially in high risk metastatic disease than low risk metastatic disease ${ }^{10}$. One of the most important points in the current study is that we showed the superiority of abiraterone use compared to $80 \mathrm{mg}$ use of bicalutamide in Japan where these drugs are often selected for the treatment of patients with high risk mHSPC in the real clinical setting.

Bertrand et al suggested that GnRH antagonist, degarelix, may be more effective than $\mathrm{GnRH}$ agonist, leuprolide, as for PSA control ${ }^{14}$. Furthermore, Kashiwabara et al reported that $\mathrm{GnRH}$ antagonist was more effective than $\mathrm{GnRH}$ agonist for $\mathrm{CAB}$ treatment of bone metastatic prostate cancer with pretreatment PSA level $\geq 50 \mathrm{ng} / \mathrm{ml}^{6}$. There are several hypotheses about the reason why $\mathrm{GnRH}$ antagonist treatment exhibits better outcome than $\mathrm{GnRH}$ agonist treatment. Previous report suggested that $\mathrm{GnRH}$ antagonist treatment decreases PSA levels at a faster pace than GnRH agonist ${ }^{14}$. This rapid effect may result in better tumor control for longer duration. From these reasons, GnRH antagonist, instead of GnRH agonist, are widely used for ADT in Japan. Currently, almost all patients who had been diagnosed as high risk mHSPC in our hospital also received GnRH antagonist instead of GnRH agonist. In the present study the PSA level decreased rapidly in both of agonist and antagonist groups and average PSA response rate after 3 months of treatment was $99 \%$ in the two groups (data not shown). Comparison of PSA-PFS and OS between $\mathrm{GnRH}$ agonist and antagonist in CAB therapy may be future work. GnRH receptor expression has been reported in various types of malignant cells including prostate cancer cells ${ }^{1516}$. It is reported that both $\mathrm{GnRH}$ agonist and antagonist decrease proliferation of prostate cancer cells ${ }^{17}$. The in vitro comparison of growth suppression effect between $\mathrm{GnRH}$ agonist and antagonist may lead to more profound understanding of differential effect between the two drugs.

This is the first report which compared the efficacy of abiraterone with bicalutamide, in combination with $\mathrm{GnRH}$ antagonist for high risk mHSPC patients in Japan. However, it is important to note that there were several limitations in the present study. The patient cohort was small, and there was a significant difference regarding patient background because of the retrospective nature of the study. Moreover, observation period was short especially in patients treated with abiraterone. Therefore, a further prospective study with a larger cohort for longer period is required. 
In conclusion, we demonstrated that abiraterone use in combination with $\mathrm{GnRH}$ antagonist instead of bicalutamide may have advantages regarding OS as well as PSA-PFS in patients with high risk mHSPC. The findings from the study could provide useful information when physicians choose a treatment plan in patients with high risk $\mathrm{mHSPC}$.

\section{Declarations}

\section{Acknowledgements}

This report is based on the results from our hospital and affiliated hospitals. We express gratitude for cooperation of urologists in affiliated hospitals. Urologists who cooperated are: Hiroaki Miyashita, So Ushijima and Toshiya Takamura, Department of Urology, Omihachiman Community Medical Center; Jintetsu So and Yuta Inoue, Department of Urology, Japanese Red Cross Daini Hospital; Shunji Harikai and Sojiro Hirano, Department of Urology, Kyoto Yamashiro General Medical Center; Yasuhiro Yamada, Kyoto Okamoto Memorial Hospital, Department of Urology; Kento Masuda, Department of Urology, Kyoto Kuramaguchi Medical Center; Tsuyoshi Iwata, Department of Urology, Kyoto Min-Iren Chuo Hospital; Kazuya Mikami and Naruhiro Kayukawa, Department of Urology, Japanese Red Cross Daiichi Hospital; Nobuhisa Hagiwara, Department of Urology, Maizuru Medical Center; Kenji Hiraoka, Department of Urology, North Medical Center Kyoto Prefectural University of Medicine; Hirokazu Ishida, Department of Urology, Uji Takeda Hospital; Kimihiro Yano, Department of Urology, Fujinomiya City General Hospital; Akihisa Ueno, Department of Urology, Saiseikai Suita Hospital; Masakatsu Oishi, Department of Urology, Aiseikai Yamashina Hosipital; Motohiro Kanazawa and Asa Nakata, Department of Urology, Kyoto Chubu Medical Center; Naoki Hirahara and Ichiro Takeuchi, Department of Urology, Kyoto Kizugawa Hospital; Hidehisa Boku, Department of Urology, Kyoto Tanabe Central Hospital; Yusuke Gabata, Department of Urology, Ayabe City Hospital.

\section{Conflict of interest}

The authors declare no conflict of interest.

\section{References}

1 Ferlay, J. et al. Estimating the global cancer incidence and mortality in 2018: GLOBOCAN sources and methods. International journal of cancer144, 1941-1953, doi:10.1002/ijc.31937 (2019).

2 Kimura, T. \& Egawa, S. Epidemiology of prostate cancer in Asian countries. Int J Uro/25, 524-531, doi:10.1111/iju.13593 (2018).

3 Hinotsu, S. et al. Current status of endocrine therapy for prostate cancer in Japan analysis of primary androgen deprivation therapy on the basis of data collected by J-CaP. Japanese journal of clinical oncology37, 775-781, doi:10.1093/jjco/hym098 (2007). 
The New England journal of medicine377, 352-360, doi:10.1056/NEJMoa1704174 (2017).

$5 \quad$ Akaza, H. et al. Combined androgen blockade with bicalutamide for advanced prostate cancer: long-term follow-up of a phase 3, double-blind, randomized study for survival. Cancer115, 3437-3445, doi:10.1002/cncr.24395 (2009).

6 Kashiwabara, T. \& Suda, S. Usefulness of combined androgen blockade therapy with gonadotropin-releasing hormone antagonist for bone metastatic prostate cancer with pretreatment prostate-specific antigen level >/= $50 \mathrm{ng} / \mathrm{mL}$. BMC cancer18, 619, doi:10.1186/s12885-018-4541-0 (2018).

7 Sano, T. et al. Impact of Cardiac Progenitor Cells on Heart Failure and Survival in Single Ventricle Congenital Heart Disease. Circ Res122, 994-1005, doi:10.1161/CIRCRESAHA.117.312311 (2018).

8 Miyoshi, Y. et al. Prognostic value of the bone scan index using a computer-aided diagnosis system for bone scans in hormone-naive prostate cancer patients with bone metastases. BMC cancer16, 128, doi:10.1186/s12885-016-2176-6 (2016).

9 Onozawa, M. et al. Combined androgen blockade achieved better oncological outcome in androgen deprivation therapy for prostate cancer: Analysis of community-based multi-institutional database across Japan using propensity score matching. Cancer Med7, 4893-4902, doi:10.1002/cam4.1735 (2018).

10 Cooperberg, M. R., Hinotsu, S., Namiki, M., Carroll, P. R. \& Akaza, H. Trans-Pacific variation in outcomes for men treated with primary androgen-deprivation therapy (ADT) for prostate cancer. BJU internationa/117, 102-109, doi:10.1111/bju.12937 (2016).

11 Shiota, M. et al. Association of Missense Polymorphism in HSD3B1 With Outcomes Among Men With Prostate Cancer Treated With Androgen-Deprivation Therapy or Abiraterone. JAMA Netw Open2, e190115, doi:10.1001/jamanetworkopen.2019.0115 (2019).

12 Scher, H. I. et al. Bicalutamide for advanced prostate cancer: the natural versus treated history of disease. Journal of clinical oncology : official journal of the American Society of Clinical Oncology15, 2928-2938, doi:10.1200/JC0.1997.15.8.2928 (1997).

13 Klotz, L. et al. An open-label, phase 2 trial of bicalutamide dose escalation from $50 \mathrm{mg}$ to 150 $\mathrm{mg}$ in men with $\mathrm{CAB}$ and castration resistance. A Canadian Urology Research Consortium Study. Prostate Cancer Prostatic Dis17, 320-324, doi:10.1038/pcan.2014.24 (2014).

14 Tombal, B. et al. Additional analysis of the secondary end point of biochemical recurrence rate in a phase 3 trial (CS21) comparing degarelix $80 \mathrm{mg}$ versus leuprolide in prostate cancer patients 
segmented by baseline characteristics. European urology57, 836-842, doi:10.1016/j.eururo.2009.11.029 (2010).

15 Limonta, P. et al. GnRH receptors in cancer: from cell biology to novel targeted therapeutic strategies. Endocr Rev33, 784-811, doi:10.1210/er.2012-1014 (2012).

16 Angelucci, C. et al. GnRH receptor expression in human prostate cancer cells is affected by hormones and growth factors. Endocrine36, 87-97, doi:10.1007/s12020-009-9195-x (2009).

17 Castellon, E. et al. Effect of leuprolide and cetrorelix on cell growth, apoptosis, and GnRH receptor expression in primary cell cultures from human prostate carcinoma. Cancer Invest24, 261-268, doi:10.1080/07357900600629591 (2006).

\section{Tables}

Table 1 Patient characteristics

\begin{tabular}{|c|c|c|c|c|}
\hline \multicolumn{2}{|l|}{ hormone therapy } & \multirow{2}{*}{$\begin{array}{l}\text { abiraterone+GnRH antagonist } \\
(\text { group } \mathrm{A}) \\
\mathrm{n}=50\end{array}$} & \multirow{2}{*}{$\begin{array}{l}\text { bicalutamide }+\mathrm{GnRH} \text { antagonist } \\
\text { (group B) } \\
\mathrm{n}=99\end{array}$} & \multirow{2}{*}{$\begin{array}{l}\text { A vs B } \\
\text { p- } \\
\text { value }\end{array}$} \\
\hline & & & & \\
\hline $\begin{array}{l}\text { Median age at diagnosis years } \\
\text { (range) }\end{array}$ & & $73.5(53-85)$ & $77(57-91)$ & $<0.001$ \\
\hline $\begin{array}{l}\text { Median pretreatment PSA level } \\
\mathrm{ng} / \mathrm{mL}\end{array}$ & & $663.68(2.72-24201)$ & $357.23(4.177-32548)$ & 0.554 \\
\hline Median pretreatment ALP & & $711(124-12122)$ & $519(126-7060)$ & 0.0411 \\
\hline \multirow[t]{4}{*}{ Pathological diagnosis } & $\begin{array}{l}\text { Gleason } \\
\text { score } 7\end{array}$ & 1 & 2 & 0.0439 \\
\hline & $\begin{array}{l}\text { Gleason } \\
\text { score } 8\end{array}$ & 8 & 26 & \\
\hline & $\begin{array}{l}\text { Gleason } \\
\text { score } 9\end{array}$ & 31 & 62 & \\
\hline & $\begin{array}{l}\text { Gleason } \\
\text { score } 10\end{array}$ & 9 & 9 & \\
\hline \multirow[t]{5}{*}{ EOD (extent of disease) score } & EOD0 & 3 & 3 & 0.0402 \\
\hline & EOD1 & 5 & 23 & \\
\hline & EOD2 & 13 & 32 & \\
\hline & EOD3 & 17 & 23 & \\
\hline & EOD4 & 11 & 14 & \\
\hline $\begin{array}{l}\text { Median observation period } \\
\text { months (range) }\end{array}$ & & $10.5(3-23)$ & $23(3-88)$ & $<0.001$ \\
\hline
\end{tabular}

Table 2 Multivariate analysis for PSA-PFS 


\begin{tabular}{lllllll}
\hline & \multicolumn{2}{l}{ Univariate analysis } & \multicolumn{4}{l}{ Multivariate analysis } \\
\cline { 2 - 7 } & HR & $95 \%$ CI & p-vslue & HR & $95 \%$ CI & p-value \\
\hline abiraterone therapy & 4.64 & $2.31-9.31$ & $<0.001$ & 7.53 & $3.48-16.30$ & $<0.001$ \\
\hline age at diagnosis years & 1.89 & $0.60-6.07$ & 0.28 & 0.42 & $0.12-1.55$ & 0.19 \\
\hline pretreatment PSA level & 1.12 & $0.11-5.55$ & 0.91 & 0.93 & $0.039-6.71$ & 0.95 \\
\hline Gleason score & 4.79 & $1.71-13.90$ & 0.0035 & 17.99 & $3.73-52.10$ & 0.0001 \\
\hline EOD (extent of disease) score & 1.68 & $0.78-3.64$ & 0.18 & 0.282 & $0.57-4.27$ & 0.40 \\
\hline pretreatment ALP level & 1.32 & $0.29-4.45$ & 0.69 & 19.027 & $0.26-9.46$ & 0.51 \\
\hline
\end{tabular}

Table 3 Characteristics of matched patients (group A and Group B)

\begin{tabular}{|c|c|c|c|c|}
\hline \multicolumn{2}{|l|}{ hormone therapy } & $\begin{array}{l}\text { abiraterone+GnTH antagonist } \\
\text { (Group A) } \\
n=28\end{array}$ & $\begin{array}{l}\text { bicaltamide+GnRH antagonist } \\
\text { (Group B) } \\
\mathrm{n}=28\end{array}$ & $\begin{array}{l}\text { A vs B } \\
\text { p- } \\
\text { value }\end{array}$ \\
\hline $\begin{array}{l}\text { Median age at diagnosis years } \\
\text { (range) }\end{array}$ & & $74(55-84)$ & $76(57-86)$ & 0.2293 \\
\hline $\begin{array}{l}\text { Median pretreatment PSA level } \\
\mathrm{ng} / \mathrm{mL}\end{array}$ & & $593.369(10.8-10559)$ & $289.205(4.177-32548)$ & 0.6462 \\
\hline Median pretreatment ALP & & $584.5(232-3927)$ & 731(199-7060) & 0.6128 \\
\hline \multirow[t]{4}{*}{ Pathological diagnosis } & $\begin{array}{l}\text { Gleason } \\
\text { score } 7\end{array}$ & 1 & 0 & 0.5568 \\
\hline & $\begin{array}{l}\text { Gleason } \\
\text { score } 8\end{array}$ & 4 & 6 & \\
\hline & $\begin{array}{l}\text { Gleason } \\
\text { score } 9\end{array}$ & 16 & 18 & \\
\hline & $\begin{array}{l}\text { Gleason } \\
\text { score } 10\end{array}$ & 7 & 4 & \\
\hline \multirow[t]{5}{*}{ EOD (extent of disease) score } & EOD0 & 1 & 0 & 0.4475 \\
\hline & EOD1 & 3 & 6 & \\
\hline & EOD2 & 10 & 10 & \\
\hline & EOD3 & 7 & 8 & \\
\hline & EOD4 & 7 & 4 & \\
\hline $\begin{array}{l}\text { Median observation period } \\
\text { months (range) }\end{array}$ & & $14.5(2-23)$ & $9.5(3-31)$ & 0.2093 \\
\hline
\end{tabular}

\begin{tabular}{llll}
\hline & \multicolumn{4}{l}{ Univariate analysis } \\
\cline { 2 - 4 } & HR & $95 \%$ CI & p-vslue \\
\hline abiraterone therapy & 7.09 & $2.45-20.56$ & $<0.001$ \\
\hline age at diagnosis years & 0.981 & $0.99-1.00$ & 0.5555 \\
\hline pretreatment PSA level & 1.12 & $0.11-5.55$ & 0.5328 \\
\hline Gleason score & 2.48 & $1.25-5.17$ & 0.0089 \\
\hline EOD (extent of disease) score & 1.31 & $0.88-2.00$ & 0.18 \\
\hline pretreatment ALP level & 1.32 & $0.99-1.00$ & 0.08 \\
\hline
\end{tabular}

Table 4 Univariate analysis for PSA-PFS in matched patients 
Figures

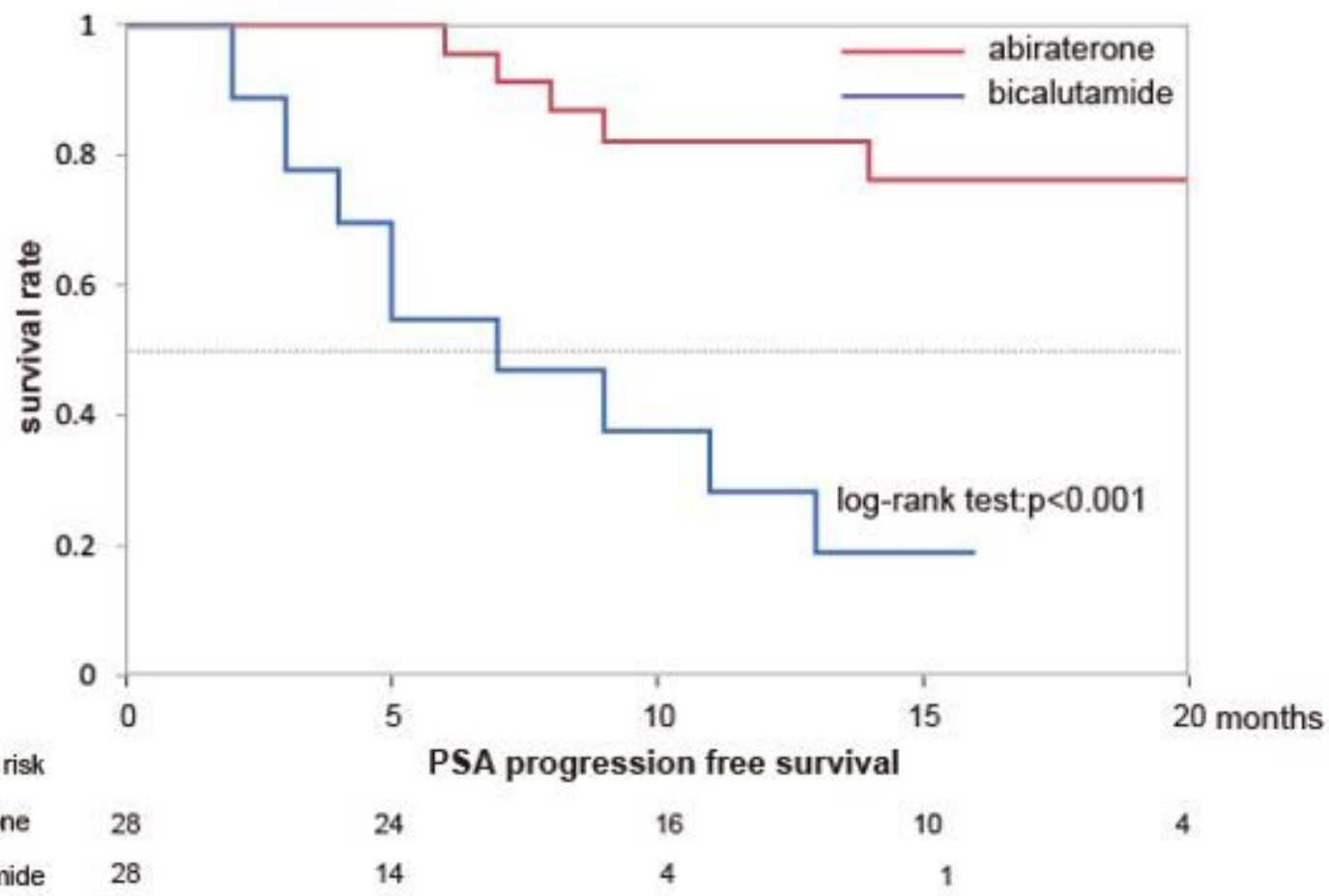

\section{Figure 1}

Kaplan-Meire estimates of PSA progression free survival in matched patients.

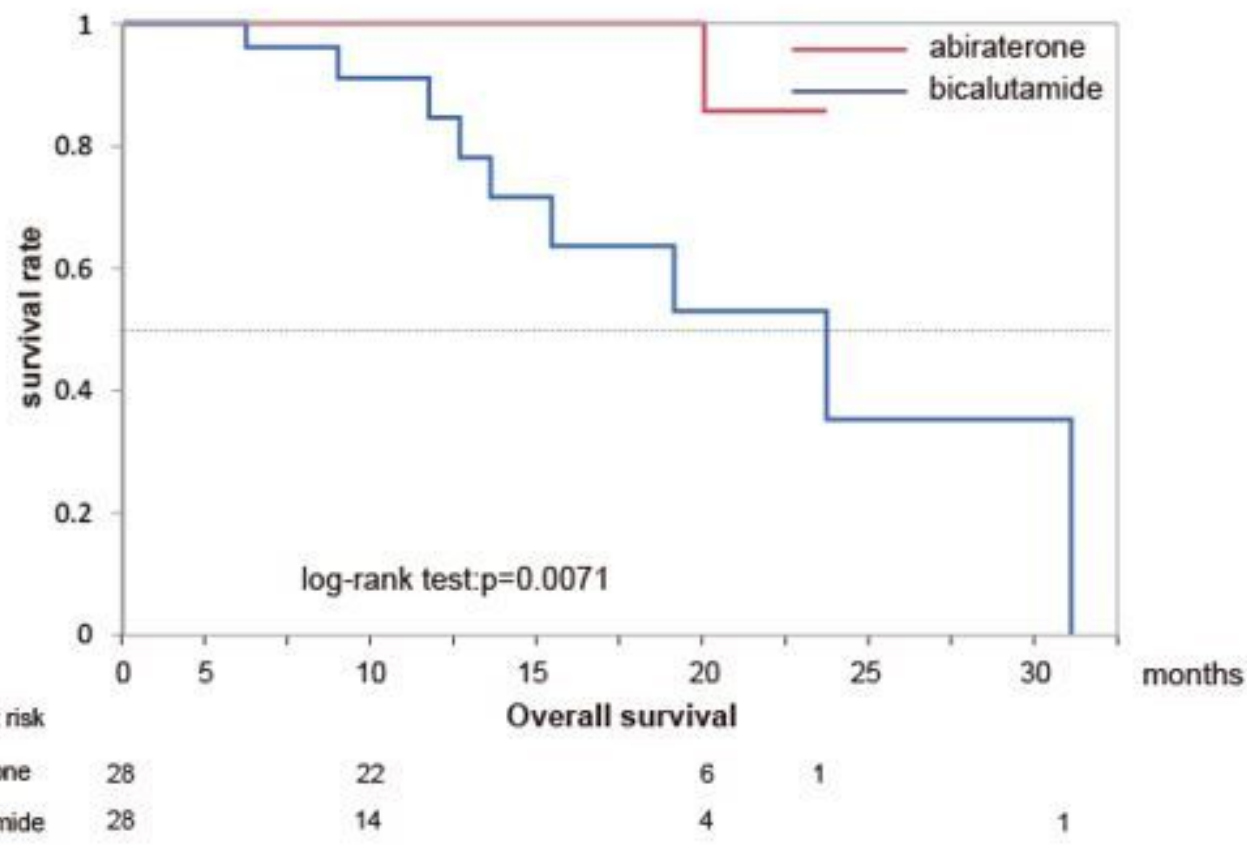

Figure 2 
Kaplan-Meire estimates of overall survival in matched patients.

\section{Supplementary Files}

This is a list of supplementary files associated with this preprint. Click to download.

- supplementaryinformationFigureS1S2.docx 